\title{
Embedding robotic surgery into routine practice and impacts on communication and decision making: a review of the experience of surgical teams
}

\author{
Rebecca Randell ${ }^{1}$ (D) Stephanie Honey ${ }^{1} \cdot$ Natasha Alvarado $^{2} \cdot$ Alan Pearman $^{3} \cdot$ \\ Joanne Greenhalgh ${ }^{4} \cdot$ Andrew Long ${ }^{1} \cdot$ Peter Gardner $^{5} \cdot$ Arron Gill $^{6}$. \\ David Jayne $^{7} \cdot$ Dawn Dowding ${ }^{8,9}$
}

Received: 9 July 2015/Accepted: 18 March 2016/Published online: 1 April 2016

(c) The Author(s) 2016. This article is published with open access at Springerlink.com

\begin{abstract}
While an increasing number of healthcare providers are purchasing surgical robots because of anticipated improvements in patient outcomes, their implementation into practice is highly variable. In robotic surgery, the surgeon is physically separated from the patient and the rest of the team with the potential to impact communication and decision making in the operating theatre and subsequently patient safety. Drawing on the approach of realist evaluation, in this article we review reports of the experience of surgical teams that have introduced robotic surgery to identify how and in what
\end{abstract}

Electronic supplementary material The online version of this article (doi:10.1007/s10111-016-0368-0) contains supplementary material, which is available to authorized users.

Rebecca Randell

r.randell@leeds.ac.uk

1 School of Healthcare, University of Leeds, Leeds LS2 9UT, UK

2 Institute of Health and Society, Newcastle University, Newcastle, UK

3 Centre for Decision Research, University of Leeds, Leeds, UK

4 School of Sociology and Social Policy, University of Leeds, Leeds, UK

5 School of Psychology, University of Leeds, Leeds, UK

6 Geoffrey Giles Theatres, Leeds Teaching Hospitals NHS Trust, Leeds, UK

7 Leeds Institute of Biomedical and Clinical Sciences, University of Leeds, Leeds, UK

8 Columbia University School of Nursing, New York, NY, USA

9 Center for Home Care Policy and Research, Visiting Nursing Service of New York, New York, NY, USA contexts robotic surgery is successfully integrated into practice and how and in what contexts it affects communication and decision making. Our analysis indicates that, while robotic surgery might bring about a number of benefits, it also creates new challenges. Robotic surgery is associated with increased operation duration, which has implications for patient safety, but strategies to reduce it can be effective with appropriate support from hospital administration and nursing management. The separation of the surgeon from the team can compromise communication but may be overcome through use of standardised communication. While surgeon situation awareness may be affected by the separation, the ergonomic benefits of robotic surgery may reduce stress and tiredness and enhance surgeon decision making. Our review adds to the existing literature by revealing strategies to support the introduction of robotic surgery and contextual factors that need to be in place for these to be effective.

Keywords Robotic surgery - Teamwork · Communication - Decision making - Awareness ·

Realist evaluation

\section{Introduction}

As a result of technological innovation, there have been great advances in surgical practice over the past three decades (Healey and Benn 2009). Traditional open surgery was challenged in the 1990s by the introduction of minimally invasive surgery (MIS), where the surgeon performs operations using small 'key-hole' incisions, through which cameras and laparoscopic instruments are passed. This removes much of the access trauma, resulting in numerous benefits for patients, including less postoperative pain, 
shorter hospitalisation, quicker return to normal function, and improved cosmetic effect (Bann et al. 2003; Dobson et al. 2011; Smith et al. 2006). However, laparoscopic surgery can be technically challenging to perform, as a result of the 2D operative image and instruments that have limited freedom of movement and require awkward and non-intuitive handling. Robotic surgery may increase uptake of MIS by overcoming some of the limitations of laparoscopic surgery (Lanfranco et al. 2004). During robotic surgery, laparoscopic instruments and a camera are inserted into the patient and held by robotic arms, which are operated remotely by the surgeon who sits at a console outside the sterile field. Depending on the model of the robot, the robot will have either three or four arms, one holding the camera, so that the surgeon is able to use either two or three instruments at a time. The robotic system provides a $3 \mathrm{D}$, magnified view of the surgical field via the camera. The multi-articulated instruments increase dexterity, while tremor reduction and motion scaling may enable more precise dissection (Smith et al. 2006). Additionally, the surgeon sits in a comfortable, ergonomically preferable position (Scarpinata and Aly 2013). While there is a lack of high-quality evidence concerning the impact of robotic surgery on patient outcomes, two randomised controlled trials comparing laparoscopic and robotic surgery for curative treatment of prostate cancer have found that, while there was no difference in oncological outcomes, robotic surgery offers health-related quality of life benefits for patients, in terms of higher rates of continence (Porpiglia et al. 2013) and sexual function (Asimakopoulos et al. 2011).

Over the last decade, there has been rapid growth in the purchase of da Vinci robots (Intuitive Surgical Inc., Sunnyvale, CA), currently the only commercially available robotic platform for soft tissue surgery (Abrishami et al. 2014). However, there are reports of underuse of these robots, suggesting that the potential benefits of robotic surgery for patients are not being fully realised (Jones and Sethia 2010). It also has implications for the cost effectiveness of robotic surgery which depends on the number of operations for which the robot is used (Scales et al. 2005). Little is known about how to effectively integrate robotic surgery into routine practice. While some quantitative studies of robotic surgery contain reflections on what supported the introduction of robotic surgery within their institution, because they are undertaken within a single institution and typically by dedicated robotic surgery enthusiasts (Smith et al. 2006), little is known about the contextual factors that are necessary for the successful integration of robotic surgery more broadly. Robotic surgery is a complex sociotechnical system (Healey et al. 2008) and the introduction of such systems into practice typically involves long implementation chains, influenced by stakeholders at different levels within and outwith the organisation (Pawson 2013). Robotic surgery is introduced into an already complex, technology rich, safety-critical environment, where team members with diverse training and expertise work together under conditions of time pressure and uncertainty (Flin et al. 2007; Pugh et al. 2011). While existing evaluations of robotic surgery have focused on the role of the surgeon (Sgarbura and Vasilescu 2010), the complex division of labour in the operating theatre (OT) means that a technology which has consequences for the role of the surgeon will inevitably have consequences for other members of the team. Successful introduction of robotic surgery is likely to involve a process through which OT personnel, both individually and as a group, adapt both the technology and the way that they work (Cook and Woods 1996; Finch et al. 2012). Such sociotechnical coupling can result in users not using the technology in the way the designers anticipated, resulting in unintended consequences that may have implications for patient safety (Ash et al. 2004).

Robotic surgery also involves a significant change in the spatial configuration of the patient, surgeon and OT team, with the surgeon working at a distance from the patient and the rest of the team. Spatial configuration has previously been identified as a performance-shaping factor in surgery (Healey et al. 2011) and could potentially impact communication and decision making in the OT. Intra-operative communication is a topic that has received much attention over recent years, due to communication breakdown being identified as a key factor in adverse events in the OT (Hull et al. 2012). In one study, communication breakdown was cited as a contributing factor in $43 \%$ of adverse events (Gawande et al. 2003). Similarly, in an analysis of surgical errors that led to malpractice claims, communication breakdown was identified as a contributing factor in $24 \%$ of claims (Rogers et al. 2006). Even when communication failures do not result in an adverse event, they can predispose to the occurrence of an adverse outcome by negatively impacting the team's ability to compensate for a major event (de Leval et al. 2000). Two small studies have looked at differences in communication between laparoscopic and robotic surgery (Cao and Taylor 2004; Nyssen and Blavier 2009; Webster and Cao 2006), both revealing a significant increase in oral communication between the surgeon and the rest of the team in robotic surgery, potentially due to the surgeon compensating for a breakdown that occurs in the collaboration between the surgeon and the team because of the removal of face to face communication (Nyssen and Blavier 2009). If use of robotic surgery interferes with standard practices of communication in the OT, patient safety may be compromised.

Whether the spatial configuration of robotic surgery and subsequent impacts on communication have consequences 
for surgeons' intra-operative decision making remains to be explored. However, there is strong evidence, both in the OT and in other contexts, that physical proximity of team members and technology influence the gathering of information that is used to inform decision making (Johnson et al. 2011; Mentis et al. 2012; Mishra et al. 2011). Situation awareness, defined as the perception of elements in the environment, the comprehension of their meaning, and the projection of their status in the near future (Endsley 1995), is recognised as an important component of surgeons' intra-operative decision making (Flin et al. 2007). If use of robotic surgery interferes with the surgeon's situation awareness, quality of decision making may be affected.

We are undertaking a process evaluation alongside a randomised controlled trial comparing laparoscopic and robotic surgery for curative treatment of rectal cancer, to explore how robotic surgery gets introduced into practice and how it impacts communication and decision making (Randell et al. 2014). Realist evaluation provides an overall framework for the process evaluation (Pawson and Tilley 1997). As a first stage in undertaking this evaluation, we reviewed reports of the experience of surgical teams that have introduced robotic surgery to identify how and in what contexts robotic surgery is successfully integrated into practice and how and in what contexts it affects communication and decision making. This is important for informing future implementations of robotic surgery and to understand the potential impacts of robotic surgery on patient safety. In this article, we present the results of that review.

\section{Methods}

Realist evaluation explicitly acknowledges the sociotechnical nature of technologies such as robotic surgery. In realist evaluation, technologies in and of themselves are not seen as determining outcomes. Rather, technologies are considered to offer resources to users and outcomes depend on how users make use of (or not) those resources, which will vary according to the context. Thus, realist evaluation seeks to answer not only the question of 'what works?' but 'what works for whom, in what circumstances, and how?' This is achieved through eliciting, testing, and refining stakeholders' theories of how the technology works. These theories, referred to as context mechanism outcome (CMO) configurations, describe the contexts in which particular mechanisms (the reasoning and responses of users) are triggered and the subsequent outcomes, where $\mathrm{C}+\mathrm{M}=\mathrm{O}$.

The relevance of critical realism for studying safetycritical sociotechnical systems has previously been argued
(Pettersen et al. 2010). Critical realism is an important precursor to realist evaluation and they share significant common ground (Pawson 2013). Where they differ is on the matter of how investigations of human behaviour in context can be conducted. From a critical realist perspective, when studying complex sociotechnical systems, it is impossible to conduct the 'closed system' investigations available to experimental science and therefore theoretical inquiry is the only option. Within realist evaluation, the argument is made that even investigations in experimental science are not closed systems; all empirical investigation can only ever achieve partial closure. Rather, understanding and explanation in experimental science is achieved through an iterative process over time of conducting experiments and refining the theory to inform the design of the next experiment. Thus, those wishing to study complex sociotechnical systems should use this approach of iterating between theory and empirical investigation.

The first stage in a realist evaluation is theory elicitation. This can be done in a number of ways, such as interviewing stakeholders, reviewing the existing literature on the topic, identifying relevant theories from the sociological or other literatures, or some combination of these approaches. To begin our realist evaluation, we carried out a review of literature related to the use of robotic surgery. This is useful to track the history and adaptation of sociotechnical systems, which can reveal important learning about technology implementation and evaluation (Pawson et al. 2014). In contrast to a full realist review, where published evidence is used to test and refine stakeholders' theories (Pawson et al. 2005), theories elicited in our review will, in subsequent phases of the evaluation, be refined through interviews with OT teams, before being tested through observations of robotic and laparoscopic operations (Randell et al. 2014).

\subsection{Searching process}

We aimed to identify papers that described practitioners' theories of how and in what circumstances robotic surgery can be integrated into clinical practice and how it may affect communication and decision making in the OT. Such theories are likely to be found in editorials, comments, letters, and news articles (Pawson et al. 2005), and so we searched MEDLINE and MEDLINE In-Process \& Other Non-Indexed Citations, limiting our search to these publication types (see Online Resource 1: Search 1). A number of searches were run on Google, and websites of relevant professional organisations (e.g. Royal College of Surgeons) and professional journals (e.g. the Annals of the Royal College of Surgeons of England, the Nursing Times, and the Health Service Journal) were searched. Discussion sections of quantitative studies of robotic surgery also 
sometimes contain such theories, so we searched MEDLINE and MEDLINE In-Process \& Other Non-Indexed Citations to identify systematic reviews and individual studies of colorectal robotic surgery and systematic reviews of general robotic surgery (see Online Resource 1: Searches 2-4). Reference lists were used to identify further relevant individual studies.

\subsection{Selection and appraisal of documents}

The purpose of the review was to identify and catalogue the theories of surgical teams who have introduced robotic surgery, rather than to assess the validity of those theories. This is because the theories will be refined and empirically tested later in the realist evaluation. Therefore, selection and appraisal of papers identified in the first phase of searching was based on relevance to the review question, rather than rigour, as is done in the theory elicitation phase of a realist review (Pawson 2006; Pawson et al. 2005). All retrieved records were screened based on title and abstract. Reviewers asked: (1) Is this about robotic surgery using the da Vinci robot (as distinct from other uses of robots in the surgical context)? and (2) Does it potentially contain ideas about how robotic surgery works, for whom, and in what circumstances? Full text copies of all potentially relevant papers were retrieved. Reviewers read the papers to determine whether they contained ideas about how robotic surgery gets introduced into practice and affects communication and decision making in the OT (the mechanisms), the contexts in which this happens, and/or the consequences of this (the outcomes).

\subsection{Data extraction, analysis, and synthesis}

Two reviewers (SH and RR) extracted authors' theories about the mechanisms through which robotic surgery gets introduced into practice and through which it affects communication and decision making in the OT, along with information on the contexts which trigger these mechanisms and the subsequent outcomes. These formed the data for the review and were recorded in a working document with links to the original source. The reviewers discussed the extracted data, drawing together data from multiple studies to develop tentative CMO configurations, which were added to and refined as further papers were identified. In developing the CMO configurations, it was often necessary to return to the papers for further detail.

To guide our thinking, we also drew on other theories existing in the literature on implementation science, communication and teamwork, and decision making. This is in line with the realist approach, which argues that the design of interventions tends to be based on a limited number of theories regarding human behaviour and therefore, rather than starting from scratch when evaluating a new intervention, researchers should also make use of existing theory (Pawson and Tilley 1997). For example, targets are an intervention that has been introduced in different forms across a range of settings, including within healthcare and education and on an international scale, with environmental targets for reducing carbon emissions and the World Health Organization's global nutrition targets, but all are based on the same underlying theories about individual and group responses to targets. In identifying theories, we were assisted by having a multidisciplinary team whose backgrounds cover a number of relevant research disciplines, providing them with knowledge of a range of potentially relevant theories (Greenhalgh et al. 2004). However, it is important not to restrict attention only to those theories already known by the reviewers (Booth et al. 2013). One recommendation is to focus on those theories that are cited in the individual studies that are retrieved (Booth et al. 2013). Given the absence of such reference to theory within the papers we had retrieved, we instead took the approach of seeking out reviews of literature in the areas of implementation science (Greenhalgh et al. 2004; Nilsen 2015; Robert et al. 2010), communication (Manojlovich et al. 2015; Weldon et al. 2013) and teamwork (Manser 2009; Paris et al. 2000; Rousseau et al. 2006; Sims et al. 2015; Xiao et al. 2013), and decision making (Mosier and Fischer 2010; Patel and Kannampallil 2015; Patel et al. 2013). In identifying theories concerning implementation, we specifically sought out theories that relate to interventions whose effective implementation is dependent on use not by individuals but by a group and, similarly, in identifying theories concerning decision making we specifically sought out theories that consider how information is shared and decisions are made within a group, rather than those which focus on individual cognition. To better understand the extent to which what we identified in the literature was unique to robotic surgery, we also drew on studies of open and laparoscopic surgery, providing a resource for comparison.

\section{Results}

The search identified 485 references which were evaluated together with 188 websites. Two hundred and twenty-eight papers and 34 websites were identified as relevant, although there was much repetition of the theories contained within them. Below we summarise key theories from the literature regarding how and why robotic surgery is successfully implemented in routine practice (or not), and how it impacts on communication and decision making. We observed an overall pattern to these theories: while robotic surgery might bring about a number of benefits, it 
also creates a number of new challenges. This prompted a need to develop strategies to overcome these challenges, and in reporting these strategies the authors also reported theories about the mechanisms through which, and circumstances in which, these strategies would be most effective. Here we report practitioners' ideas and opinions about how robotic surgery might work. As noted above, the intention was to catalogue the theories identified, rather than to assess their validity. However, we have sought to indicate where there is evidence to support these theories and which theories were presented without supporting evidence.

\subsection{How does robotic surgery become embedded into routine practice?}

In most studies that described the introduction of robotic surgery, this had been led by surgeons, but the importance of obtaining the support of the hospital administration and nursing management was emphasised. In surgeons' reports of the experience of introducing robotic surgery into their organisation, this support was described as being necessary to ensure provision of adequate resources while staff are on the learning curve, such as additional OT time (Huettner et al. 2010; Toro et al. 2015). How to obtain this support is unclear, although one report of the experience of introducing robotic surgery described the need to create a 'shared vision' of what the introduction of robotic surgery will enable, starting with the administrators (Payne and Pitter 2011). This fits with existing literature that indicates that complex interventions are more easily embedded into routine practice if they align with the goals of both top and middle management and if leaders are actively involved and consulted (Greenhalgh et al. 2004). The underlying theory seems to be that, by being engaged in this process of imagining potential future benefits of robotic surgery, the hospital administration and nursing management will perceive robotic surgery as an innovation that can assist in achieving the organisation's goals and so will be willing to invest the necessary resources to assist its integration into routine practice. In the language of the theory of implementation climate, we can see this as a strategy for strengthening the organisation's climate for implementation of robotic surgery, which in turn should encourage use of the intervention, in part by removing obstacles to use of the intervention (Klein and Sorra 1996).

However, robotic surgery was perceived to introduce its own challenges. For example, surgeons' reports of the experience of robotic surgery describe how the bulk of the robot makes it difficult to manoeuvre (Huettner et al. 2010; Toro et al. 2015). In some review articles, authors have argued that this represents a patient safety issue if prompt conversion to open surgery becomes necessary so the robot needs to be moved out of the way (Baik 2008; Fung and Aly 2013), although the extent to which this has caused problems in practice is unclear. This challenge may reduce the willingness of surgeons to undertake robotic surgery, particularly for multi-quadrant operations that require the robot to be repositioned during the operation. Another challenge is that, across a number of non-randomised studies, robotic surgery has also been found to extend operation duration. This not only increases costs by increasing staff and OT time, but some authors have argued that it can put patients at risk from complications caused by being under anaesthesia for longer (Parra-Davila and Ramamoorthy 2013), although it is unclear to what extent such complications have arisen in practice.

We identified conflicting theories about how robotic surgery increases operation duration. Some authors, based on reviews of case series and non-randomised studies, argue that it is due to the time required to set up and dock the robot (Antoniou et al. 2012; Bencini et al. 2015). Others, on the basis of early case series and personal experience, point to time required to reposition and re-dock the robot during multi-quadrant operations (Hance et al. 2004; Luca et al. 2009). Yet others point to a longer operative time, identified through retrospective analysis of robotic and laparoscopic operations undertaken within their institution, which they perceived as being due to collisions of the robotic arms, itself a consequence of lack of experience with proper positioning of the robotic ports (Kwak et al. 2011).

It has also been argued that longer operation duration is related to the lack of tactile information (Lim et al. 2013). In open surgery, surgeons work primarily with visual and tactile information. In laparoscopic surgery, although tactile information is reduced, randomised experimental studies with both novice and experienced surgeons have revealed that, by touching with the instruments, surgeons are still able to determine features of objects such as shape, texture, and consistency (Bholat et al. 1999a, b). In contrast, in robotic surgery the surgeon receives no tactile information. Thus, the underlying theory is that the lack of tactile information means that surgeons move more slowly because they have to rely on visual information only.

One study, a retrospective case control study of 263 patients who underwent either robotic or laparoscopic curative surgery for colonic cancer, found no difference in overall duration, because although the set-up time was significantly longer, this was balanced out by a significantly shorter operative time (Helvind et al. 2013). The authors of this study argue that the shorter operative time is due to the technical advantages the robot provides to the surgeon.

Given the high cost of purchasing and maintaining a robotic system (Alasari and Min 2012; Antoniou et al. 
2012; Averbach et al. 2010), with the latest model of the da Vinci robot costing between $\$ 1.85 \mathrm{~m}$ abd $\$ 2.3 \mathrm{~m}$ and annual maintenance fees of several thousand dollars per robot, minimising additional costs associated with increased operation duration may be essential for ensuring robotic surgery gets integrated into routine practice.

\subsubsection{What strategies might reduce operation duration?}

Overall, there is broad agreement in the perception that operation duration decreases as experience increases, supported by evidence from both randomised and non-randomised comparative studies, with this often being attributed to a decrease in set-up time (Alasari and Min 2012; Lin et al. 2011; Turchetti et al. 2012). Thus, the underlying theory is that when the team is experienced and well trained, their knowledge and experience enables them to quickly undertake the tasks required for setting up the robot. With experience, surgeons have reported that they find visual cues are sufficient for estimating the tension exerted on the tissue (Du et al. 2013). As familiarity with positioning the robot increases, there should be fewer collisions of the robotic arms, also helping to reduce operation duration (Kwak et al. 2011).

Several strategies which might reduce operation duration by accelerating the acquisition of experience were reported. One strategy, described in surgeons' reports of the experience of introducing robotic surgery into their organisation, is to have a dedicated robotic team (D'Annibale et al. 2004; Guru and Menon 2011; Ho et al. 2013; Huettner et al. 2010; Meehan and Sandler 2008; Parra-Davila and Ramamoorthy 2013; Patel 2006; Payne and Pitter 2011; Ramirez et al. 2012) who can 'work through the learning curve and, if possible, all robotic cases' (Higuchi and Gettman 2011). The underlying theory is that by working through all robotic cases, the team more quickly becomes familiar and confident with the equipment and tasks associated with setting up the robot, allowing members to complete the necessary tasks more quickly, reducing set-up time. This fits with the broader literature on teamwork in healthcare, which suggests that a team with inconsistent team membership is more likely to experience problems related to a lack of common understanding of tasks and procedures (Xiao et al. 2013). While typically discussed in relation to the surgeon's learning curve (Whiteside 2008), the theory suggests the number and frequency of robotic operations that take place within the organisation is a contextual factor that impacts on the effectiveness of this strategy. Other contextual factors are level of motivation (Payne and Pitter 2011) and stability of the team (Goldstraw et al. 2007). Thus, a team which is not motivated may work through the robotic operations but not engage with them as an opportunity to learn and consequently increased experience of robotic surgery may not translate into increased efficiency in robot set-up. What is meant by a motivated team and what leads to a team being motivated are not specified but the theory of implementation climate suggests that, regardless of the strength of an organisation's climate for implementation of an intervention, committed and enthusiastic use of that intervention requires team members to perceive use of the intervention as fitting with their values; without this, the best that can be hoped for is compliant use (Klein and Sorra 1996). Studies of the introduction of other complex interventions into surgery emphasise the important role of the surgeon in communicating to team members the benefits of the intervention for patients in order for team members to perceive use of the intervention as fitting with their values (Edmondson et al. 2001).

Another strategy described in surgeons' reports of the experience of introducing robotic surgery into their organisation is to have the duties of the team defined and standardised (Payne and Pitter 2011). The underlying theory is that, where there are clear agreed roles amongst the team, there is less for individual team members to learn, meaning they learn their assigned tasks more quickly and know what is expected of them. This knowledge means they carry out their tasks without prompting, leading to improved coordination of tasks and subsequently reduced operation duration. This fits with existing literature on interprofessional teamwork in healthcare which suggests that role clarity leads not only to team members understanding the demands of their own roles but also understanding others' roles and being aware of the specific skills and expertise of their colleagues (Sims et al. 2015). Theories of team decision making indicate that such knowledge of the roles of other team members enables team members to carry out their roles in a timely and coordinated way, with little negotiation of what to do and when (Orasanu and Salas 1993). In line with this, role clarity has been identified as a performance-shaping factor in surgery (Healey et al. 2011). Having the duties of the team defined and standardised can also enable 'parallel-tasking', where key tasks take place concurrently. By reducing unnecessary waiting periods, this is thought to increase safety and efficiency and again contribute to reduced operation duration (Maan et al. 2012). It is argued that the effectiveness of this strategy is dependent on having an enthusiastic team, which is motivated to learn its tasks and perform them efficiently (Payne and Pitter 2011), and presumably on frequency of robotic operations; if teams do not get to practise what they have learnt through repeated, frequent operations, it will be harder to establish a routinised way of working. Again, team stability is important, with literature on team decision making indicating that such stability supports team members in gaining knowledge of each other's roles (Orasanu and Salas 1993). 
Another strategy for reducing operation duration mentioned in surgeons' reports of the experience of introducing robotic surgery into their organisation is to have additional OT staff (Rawlings et al. 2007). The underlying theory is that, by assisting with setting up and clearing away the robot, additional staff can reduce set-up time and speed turnover to the next case. However, given the challenge of the learning curve, it could be assumed additional staff also need to gain experience in the set-up of the robot for this strategy to work as intended. A number of surgeons also recommend having a dedicated robotic OT (Huettner et al. 2010; Kariv and Delaney 2005), meaning the bulky robot does not need to be moved between OTs, reducing time spent setting up and putting away the robot and thereby reducing overall operation duration.

While discussion of context in realist evaluation is typically concerned with the contexts that determine whether or not a strategy is effective, even being able to introduce the strategies described above is dependent upon the support of hospital administration and nursing management. This support facilitates scheduling of rotas to enable a robotic team to develop, to assign additional staff, and to agree to the creation of a dedicated robotic OT. Also important are the financial and material resources of the hospital; the feasibility of having additional staff depends on the number and availability of suitably experienced staff, while the feasibility of having a dedicated OT depends on the availability of OTs and the frequency of robotic operations.

\subsection{How does robotic surgery impact communication?}

Robotic surgery also introduces challenges in communication. Communication in the OT is defined as 'the quality and quantity of information exchanged among members of the team' (Healey et al. 2004). Reporting on their experience of undertaking robotic surgery, surgeons have described how the physical separation of the surgeon from the rest of the team and lack of visual contact make it harder for the team to hear the surgeon's oral instructions (Huettner et al. 2010), particularly if the surgeon becomes immersed in the console (Payne and Pitter 2011). Consequently, it has been suggested that the team needs to listen more carefully (Huettner et al. 2010), again implying the need for a motivated team. There is a perception that, if the team does not respond in this way, communication is compromised (Fung and Aly 2013; Huettner et al. 2010). A consequence of this may be a further increase in operation duration, as an observational study of 160 surgical procedures found communication failure to be a significant predictor of deviation in expected length of operation (Gillespie et al. 2012).
However, while the surgeons' accounts focus on oral communication, communication occurs through verbal and non-verbal channels and studies of open and laparoscopic surgery suggest that it is non-verbal communication, including gestures, eye gaze, and bodily orientations, that initiate much of what the theatre team do (Bezemer et al. 2011; Weldon et al. 2013).To better understand why these communication challenges occur, it is important to remember that communication is a complex multilayered representation, combining physical artefacts, gesture, and speech, where no single layer is complete or coherent by itself (Hutchins and Palen 1997). When we look at open and laparoscopic surgery, we see that the surgeon is able to use both verbal and non-verbal channels when instructing the rest of the team, for example naming an instrument while putting out their hand, indicating that they are requesting that instrument. In contrast, when we look at robotic surgery, we see that the physical separation of the surgeon from the rest of the team not only makes it harder for the team to hear the surgeon but means that the surgeon cannot use gestures to support the team's interpretation of an instruction. This suggests that the challenge for the team is not necessarily only about hearing the instruction but also interpreting it.

The different spatial configuration in robotic surgery may also impact the ability of the team to anticipate the surgeon's instructions. Previous research has highlighted how much of a scrub nurse's actions can be described as anticipatory movements, where the scrub nurse undertakes an action without the surgeon having to request it (Zheng et al. 2009). Here, we can draw on the notion of prospective sensemaking (Rosness et al. 2015), which builds on Weick's (1995) theory of organisational sensemaking. Prospective sensemaking is defined as 'sensemaking processes where the attention and concern of people is primarily directed at events that may occur in the future' (Rosness et al. 2015, p.55). It relies on both verbal and nonverbal communication, including observation of the actions of others and the effects of those actions. If the scrub nurse is physically separate from the surgeon and therefore has less access to non-verbal cues, their ability to anticipate requests may be negatively impacted, leading the surgeon to perceive that communication and coordination is harder with robotic surgery.

Use of directional cues is considered to be problematic in robotic surgery, potentially resulting in confusion, time wasting and patient injury (Higuchi and Gettman 2011). This problem occurs, presumably, because the separation means team members do not have the same physical context as the surgeon to understand such deictic instructions and again the surgeon is unable to support those instructions with gestures. 
Communication between the surgeon and the surgical assistant is considered to be particularly important in robotic surgery, especially during instrument exchanges, where failure in communication could lead to 'inadvertent adjustment, movement and complete removal of an instrument that is in use' (Higuchi and Gettman 2011). However, it has also been argued that less coordination and communication may be required between the surgeon and the assistant (Ng et al. 2009) because the surgeon controls the camera and, if four robotic arms are used, can do some of the retraction (instead of the assistant) (Koh et al. 2011). Certainly robotic surgery changes the division of labour between the surgeon and the assistant and reduces the level of task interdependence. Theories of teamwork suggest that when the level of task interdependence is low, less interaction is needed between team members to attain their goals and consequently the extent to which teamwork behaviours are required is reduced (Rousseau et al. 2006).

\subsubsection{What strategies might overcome the challenges to communication?}

Strategies for overcoming the communication challenges focus on use of standardised communication. Use of 'readback', where team members repeat back instructions in a precise, clear, standardised manner, has been advocated (Payne and Pitter 2011), particularly for instrument exchanges and other key transition points. This allows the surgeon to check his or her instructions have been heard correctly (remembering that, being in the console, they are not able to draw on visual cues to determine this) and, if not, to correct any misunderstandings before they result in actions that could have negative consequences for the patient. Research from the safety literature suggests that use of readback in surgery is beneficial regardless of whether the operation is robotic, increasing situation awareness, reducing anxiety that a request was not heard, and reducing the likelihood of forgetting the request (Guerlain et al. 2008). Use of agreed terms is recommended for robotic surgery, presumably to reduce the risk of misunderstandings (Higuchi and Gettman 2011). Use of anatomic or OT references by the surgeon, rather than directional cues, has been recommended while moving the patient or robot during docking, again to reduce the risk of misunderstandings (Higuchi and Gettman 2011).

The success of such strategies is likely to be dependent on having a dedicated, motivated team so particular communication practices, if specific to robotic surgery, can become established. This fits with Gillespie et al.'s (2010) theoretical model of team communication in surgery which suggests that communication and coordination are improved when teams are familiar with the surgeon and procedure.

\subsection{How does robotic surgery impact decision making?}

There are competing theories in the literature concerning the impact of robotic surgery on decision making. On the basis of their experience of introducing robotic surgery, some surgeons have reported a 'tendency for surgeons to bury themselves in the console,' with surgeons 'block[ing] out the operating room' (Payne and Pitter 2011). This suggests a reduction in the surgeon's situation awareness.

Naturalistic decision making (NDM) research focuses on decisions made by knowledgeable and experienced decision makers within the context of larger dynamic tasks, often with significant consequences and under intense time pressure, and thus is appropriate when considering decision making in the operating theatre (Orasanu and Connolly 1993). Situation assessment, the process by which the decision maker assesses the situation with respect to its possibilities for different types of actions, is identified as a critical element in a number of NDM models, such as Noble's Situation Assessment and Klein's Recognition Primed Decisions (RPD) (Lipshitz 1993; Noble 1993). For example, RPD highlights the importance of context or situation in 'triggering' mental models that guide decision making in numerous complex decision situations (Klein 2008). One model of intra-operative decision making suggests a continuous cycle where, with the preoperative plan in mind, the surgeon assesses the situation, reconciles new information with existing information, and subsequently implements a revised course of action (Cristancho et al. 2013). In this cycle, through the use of existing mental models, information may be actively sought or, by remaining observant of what is happening in the OT, perceived without active seeking. Such theories would suggest that a reduction in the surgeon's ability to assess the situation due to their position in the console, leading to reduced situation awareness, has the potential to negatively impact surgeon decision making. This is supported by studies that have found that better situation awareness of the surgeon is associated with fewer surgical errors (Catchpole et al. 2008; Mishra et al. 2008).

However, such theories all focus on the individual cognition of the surgeon, without consideration of how the broader OT team contributes to the surgeon's situation awareness. In the safety literature, it has been argued that decision making in robotic surgery should be seen as collaborative (Healey and Benn 2009) because, unable to see the patient directly, the surgeon is more dependent on the rest of the team communicating the status of the patient to maintain situation awareness (Healey and Benn 2009; Lai and Entin 2005). The term 'team situation awareness' refers to the extent to which each team member has the situation awareness necessary for their responsibilities 
(Endsley and Robertson 2000). Because all teams have some division of labour, not all team members will have the same situation awareness requirements. However, because they have shared goals and their actions are interdependent, they will also have some shared situation awareness requirements. Thus, in robotic surgery, the members of the OT team need not only to have awareness of those elements of the situation that are relevant for their own roles and responsibilities, it is also necessary that at least some team members have awareness of the patient state and what is going on in the wider OT, so as to be able to communicate that information to the surgeon.

Distributed cognition is a theory that encourages us to look beyond individual cognition to consider the "cognitive system', including how representations of the state of the system get propagated through the system (Hutchins $1995 \mathrm{a}, \mathrm{b})$. Thus, it is necessary to think about not only what information the surgeon and other members of the team have access to but also how that information is propagated through the system. That different members of the OT team have access to different information is not unique to robotic surgery, with previous studies of surgery demonstrating that the spatial configuration of OT teams is not arbitrary but affords particular views of the patient, the rest of the team, and different tools and technologies. Consequently, what is key is how that information is shared. For example, Hazlehurst et al. (2007) describe how in cardiac surgery the surgeon and perfusionist each have only partial access to the information that is necessary for a successful outcome, with situation awareness for both being achieved through oral exchange. This means that the challenges that robotic surgery presents for communication may have negative consequences for decision making.

Distributed situation awareness (DSA) (Stanton et al. 2006) is a theory that has much overlap with the ideas of distributed cognition, with both emphasising the role of both human and non-human agents and with both recognising that different agents have different views of the same scene, but while distributed cognition refers broadly to information that is represented and propagated throughout the system, DSA is focused specifically on where situation awareness is present in the system. Three of the fundamental principles on which DSA is based are particularly relevant to the current discussion. The first principle is that whether or not one agent's situation awareness overlaps with that of another depends on their respective goals, with shared situation awareness not necessarily being a requirement for effective decision making within the team (in contrast to the analysis by Endsley and Robertson (2000) of team situation awareness, which suggests that goals will be shared and actions will be interdependent, so some shared situation awareness will always be required). Thus, it may not matter if the surgeon has reduced awareness of what is happening in the OT if what is essential for the decisions he or she is making is their awareness of the surgical site, in terms of the patient's anatomy and the progress of the operation. The second principle is that one agent may compensate for degradation in situation awareness in another agent. Thus, the surgeon's reduced awareness of what is happening in the OT is not problematic if other members of the OT team are monitoring the OT, understand what changes in the OT the surgeon needs to be made aware of, and do so when such changes occur. This may in fact be more effective than OT team members notifying the surgeon of all changes within the OT. The third principle is that communication between agents for supporting situation awareness may include nonverbal behaviour, customs, and practice. This suggests that barriers to oral communication are not necessarily problematic for the maintenance of situation awareness, although the physical separation that prevents the surgeon seeing others' actions may be.

There may also be beneficial impacts of robotic surgery on surgeon decision making. It is known that distractions and interruptions during complex tasks can lead to information overload, negatively impacting decision making performance due to a reduction in the number of cues attended to (Speier et al. 1999). More severe distractions and interruptions may lead decision makers to use heuristics, take shortcuts, or opt for a satisficing decision. It has been argued that, immersed in the console, the surgeon's 'distractibility' is reduced, which could potentially have a positive impact on patient outcomes (Deutsch et al. 2012), presumably due to fewer distractions resulting in improved decision making. This is supported by recent research which reveals that the number of intra-operative interruptions is significantly associated with surgeons' experienced distraction and that interruptions in the form of case-irrelevant communication in particular are linked to increased surgeon distraction (Weigl et al. 2015). Others suggest that the 3D image creates a sense of immersion, which presumably contributes to the reduced distractibility (Spitz 2013). Certainly, experimental studies suggest that, when experienced in robotic surgery, surgeons' performance is improved using the robot in $3 \mathrm{D}$, compared to using the robot in $2 \mathrm{D}$ or using laparoscopy, although the mechanism through which this improved performance is achieved remains to be further explored (Blavier and Nyssen 2014). However, it may be that the reduction in cognitive load that results from fewer distractions and interruptions is balanced out or even outweighed by increased cognitive load from controlling up to three instruments and the camera (whereas in a laparoscopic operation the surgeon would hold a maximum of two instruments and the camera would be controlled by the assistant). 
Robotic surgery may also impact surgeon decision making by reducing the surgeon's level of stress. Although not supported by empirical data, some surgeons have argued that stress arising from a difficult operation may lead a surgeon to decide to convert from laparoscopic surgery to open surgery (Luca et al. 2009). An advantage claimed for robotic surgery is that it removes the awkward and unnatural movements required during laparoscopy (Lee et al. 2005) and enables the surgeon to sit down comfortably at the console (Kanji et al. 2011), which should reduce physical discomfort and make the operation technically easier to complete. This leads to the theory that, due to the ergonomic benefits of robotic surgery, surgeon stress is reduced which may influence the decision of whether to convert, potentially resulting in a lower rate of conversion (Luca et al. 2009). Certainly, physical discomfort has been identified as an interoperative stressor and, while stress can have both positive and negative effects, undue levels of stress have been found to impair judgment and decision making (Wetzel et al. 2006). Stress reduction, as a mechanism to reduce conversion rates, is likely to occur in contexts where the surgeon is experienced, as use of new technology in itself may cause stress (Stahl et al. 2005). However, results from experimental studies looking at the impact of robotic surgery on physical and mental stress are inconclusive. While two studies involving medical students found that robotic surgery leads to lower mental and physical stress (Stefanidis et al. 2010; van der Schatte Olivier et al. 2009), in a study involving surgeons the difference was not statistically significant (Berguer and Smith 2006). Research has also found a strong association between operation duration and all aspects of surgeon workload, with longer cases being associated with greater mental fatigue and greater stress, suggesting that the longer duration of robotic operations, if not addressed, could have negative consequences for surgeon decision making (Weigl et al. 2015).

Robotic surgery also impacts surgeon decision making by changing the ability of the surgeon to use tactile perception to determine anatomic information, as described above. This is considered to be a major limitation of robotic surgery (Simorov et al. 2012). A contextual factor that is significant here is the surgeon's experience, with surgeons finding visual information sufficient for informing their decision making as their experience of robotic surgery increases (Du et al. 2013). This fits with the findings of experimental studies exploring this issue (Hagen et al. 2008), as well as Klein's (2008) RPD model which emphasises the role of experience in enabling the triggering of mental models that guide decision making.

\subsubsection{What strategies might overcome the challenges to decision making?}

To improve surgeons' situation awareness, some surgeons recommend positioning the console so that the surgeon has a clear view of the patient, so that when the surgeon looks up from the console they immediately see the patient (Higuchi and Gettman 2011). However, the success of such a strategy is likely to depend on the extent to which surgeons immerse themselves in the console (Payne and Pitter 2011). While not a strategy described in the literature, the theory of DSA suggests the need to reflect on what aspects of the situation the surgeon needs to be aware of in order to support the decisions that he or she is making, while both DSA and distributed cognition encourage consideration of the role that other members of the OT team can play in contributing to the surgeon's situation awareness.

\section{Discussion}

Our review demonstrates that robotic surgery presents a series of challenges that need to be overcome if robotic surgery is to be successfully integrated into routine practice. We identified a range of strategies OT teams had introduced locally to overcome the challenge of increased operation duration associated with robotic surgery, summarised as CMO configurations in Table 1. Many of the quantitative studies of robotic surgery that were included in the review were small case series (descriptive non-randomised studies) undertaken within a single institution and thus our review adds to the existing literature by drawing together and finding patterns in the experiences of multiple OT teams.

The development of strategies that support the introduction of robotic surgery can be considered as a form of customisation of robotic surgery. This is a feature of many sociotechnical systems, particularly those implemented across multiple local institutions (Manzano-Santaella 2011). By adopting a realist approach to our literature review, we were able to document the circumstances in which and process through which this customisation took place, enabling us to reveal not only the strategies that support the introduction of robotic surgery but also the contextual factors that need to be in place for these strategies to be effective. As such, this is a methodology that would be useful to understand the process through which other complex sociotechnical systems are implemented in practice. Our review also highlights the benefits of using existing theory to understand the implementation of complex sociotechnical systems. A contextual factor that recurred in relation to a number of the strategies for 
Table 1 Strategies for reducing operation duration

\begin{tabular}{|c|c|c|c|c|c|}
\hline \multirow[t]{2}{*}{ Context } & \multirow[t]{2}{*}{+} & \multicolumn{2}{|l|}{ Mechanism } & \multirow[t]{2}{*}{$=$} & \multirow[t]{2}{*}{ Outcome } \\
\hline & & Resource & Response & & \\
\hline $\begin{array}{l}\text { Motivated and stable team } \\
\text { High number of frequent }\end{array}$ & + & $\begin{array}{l}\text { Dedicated robotic } \\
\text { team }\end{array}$ & $\begin{array}{l}\text { Team sees operations as opportunity to learn and more quickly } \\
\text { become familiar and confident with equipment and tasks }\end{array}$ & $=$ & $\begin{array}{l}\text { Reduced set-up } \\
\text { time }\end{array}$ \\
\hline robotic operations & \multirow[t]{2}{*}{+} & \multirow{2}{*}{$\begin{array}{l}\text { Standardised } \\
\text { duties }\end{array}$} & \multirow{2}{*}{$\begin{array}{l}\text { Team members more quickly learn assigned tasks, carrying out } \\
\text { tasks in parallel without prompting }\end{array}$} & \multirow[t]{2}{*}{$=$} & Improved \\
\hline $\begin{array}{l}\text { Support of hospital } \\
\text { administration and nursing } \\
\text { management }\end{array}$ & & & & & $\begin{array}{l}\text { coordination } \\
\text { Reduced } \\
\text { operation } \\
\text { duration }\end{array}$ \\
\hline $\begin{array}{l}\text { Support of hospital } \\
\text { administration and nursing } \\
\text { management }\end{array}$ & \multirow[t]{2}{*}{+} & \multirow[t]{2}{*}{ Additional staff } & \multirow[t]{2}{*}{ Assist with setting up and clearing away robot } & \multirow[t]{2}{*}{$=$} & $\begin{array}{l}\text { Reduced set-up } \\
\text { time } \\
\text { Ouicker }\end{array}$ \\
\hline $\begin{array}{l}\text { Availability of additional staff } \\
\text { with experience of robotic } \\
\text { set-up }\end{array}$ & & & & & $\begin{array}{l}\text { turnover to } \\
\text { next case }\end{array}$ \\
\hline $\begin{array}{l}\text { Support of hospital } \\
\text { administration and nursing } \\
\text { management }\end{array}$ & \multirow[t]{2}{*}{+} & \multirow[t]{2}{*}{$\begin{array}{l}\text { Dedicated robotic } \\
\text { operating } \\
\text { theatre }\end{array}$} & \multirow[t]{2}{*}{$\begin{array}{l}\text { Team does not need to move robot from/to another location } \\
\text { before/after operation }\end{array}$} & \multirow[t]{2}{*}{$=$} & $\begin{array}{l}\text { Reduced set-up } \\
\text { time } \\
\text { Quicker }\end{array}$ \\
\hline $\begin{array}{l}\text { Availability of suitably sized } \\
\text { operating theatre }\end{array}$ & & & & & $\begin{array}{l}\text { turnover to } \\
\text { next case }\end{array}$ \\
\hline
\end{tabular}

accelerating the acquisition of experience was having a motivated team. While the literature did not specify what is meant by a motivated team or what leads to a team being motivated, by drawing on existing theories of implementation we were able to clarify this.

The review identified less literature concerned with the impact of robotic surgery on communication and decision making in the OT. However, the findings of the review suggest that robotic surgery can negatively impact communication. This is due to the physical separation of the surgeon from the rest of the team, which makes it harder for the team to hear the surgeon's requests but also limits the surgeon's ability to use gestures to support their communication. The negative impact of robotic surgery on communication is likely to be greater if the team is not motivated, while the strategies for improving communication are more likely to be effective with a dedicated, motivated team. The surgeon's position within the console may negatively impact the surgeon's situation awareness. The possibility for the team to play a role in overcoming this may be limited by the physical separation and the communication challenges associated with robotic surgery. However, there may be benefits for decision making, arising from reduced stress and tiredness due to the ergonomic benefits of the robot, particularly for surgeons who are more experienced with robotic surgery, and reduced distractability.

The findings of our review have implications for the evaluation of complex sociotechnical systems. There have been calls for better descriptions of surgical interventions when reporting evaluations (Cook et al. 2013) and the findings of this review point to the need for evaluations of robotic surgery to report not only, for example, the model of da Vinci robot used but also the various strategies put in place to support its use. For others to take up these strategies and for those strategies to have the anticipated effect, it is not enough simply to describe the strategy; information about how it produces the desired outcome and in what context is necessary. Similarly, other domains would benefit from greater reporting of the strategies that support the integration of sociotechnical systems and the circumstances in which they are effective. The findings also act as an important reminder that surgical interventions, and sociotechnical systems more generally, are not static. Evaluations of sociotechnical systems often capture the use of a technology at a single point in time. We would suggest that evaluations of sociotechnical systems need to track how the technology changes over time as users respond to and find ways overcome the challenges that the technology presents.

While the literature identified in the review was concerned with the experience of surgical teams, the included papers were almost exclusively written by surgeons. It is essential that any study of robotic surgery captures the perspectives of all professional groups that make up the OT team (Healey and Benn 2009). In the next stage of this research, the $\mathrm{CMO}$ configurations elicited in our review will be explored in interviews with surgeons, anaesthetists, and OT teams (Randell et al. 2014). This will provide an opportunity to draw on their experience in order to better understand the challenges that robotic surgery presents for communication and decision making in the OT, the 
situations in which those challenges occur, and the strategies used for overcoming them. These theories will then be tested through the observation and video recording of both robotic and laparoscopic operations in a multi-site study.

\section{Conclusion}

Drawing on the approach of realist evaluation, this article has reviewed reports of the experience of OT teams who have introduced robotic surgery. While robotic surgery might bring about a number of benefits, it is clear that it also creates new challenges, prompting the development of strategies to overcome these challenges. Our review adds to the existing literature by drawing together and finding patterns in the experiences of multiple OT teams and by revealing the strategies that support the introduction of robotic surgery and the contextual factors that need to be in place for these strategies to be effective.

Acknowledgments The authors would like to thank Jon Hindmarsh for his feedback on this article. This research is funded by the National Institute for Health Research (NIHR) Health Services and Delivery Research (HS\&DR) Programme (Project Number 12/5005/ 04). The views and opinions expressed therein are those of the authors and do not necessarily reflect those of the HS\&DR Programme, NIHR, NHS or the Department of Health.

\section{Compliance with ethical standards}

Conflict of interest The authors declare that they have no conflict of interest.

Open Access This article is distributed under the terms of the Creative Commons Attribution 4.0 International License (http://crea tivecommons.org/licenses/by/4.0/), which permits unrestricted use, distribution, and reproduction in any medium, provided you give appropriate credit to the original author(s) and the source, provide a link to the Creative Commons license, and indicate if changes were made.

\section{References}

Abrishami P, Boer A, Horstman K (2014) Understanding the adoption dynamics of medical innovations: affordances of the da Vinci robot in the Netherlands. Soc Sci Med 117:125-133. doi:10. 1016/j.socscimed.2014.07.046

Alasari S, Min BS (2012) Robotic colorectal surgery: a systematic review. ISRN Surg 2012:293894. doi:10.5402/2012/293894

Antoniou SA, Antoniou GA, Koch OO et al (2012) Robot-assisted laparoscopic surgery of the colon and rectum. Surg Endosc 26:1-11. doi:10.1007/s00464-011-1867-y

Ash JS, Berg M, Coiera E (2004) Some unintended consequences of information technology in health care: the nature of patient care information system-related errors. J Am Med Inform Assoc 11:104-112

Asimakopoulos AD, Pereira Fraga CT, Annino F, Pasqualetti P, Calado AA, Mugnier C (2011) Randomized comparison between laparoscopic and robot-assisted nerve-sparing radical prostatectomy. J Sex Med 8:1503-1512. doi:10.1111/j.17436109.2011.02215.x

Averbach M, Popoutchi P, Marques OW Jr, Abdalla RZ, Podgaec S, Abrao MS (2010) Robotic rectosigmoidectomy-pioneer case report in Brazil. Current scene in colorectal robotic surgery. Arq Gastroenterol 47:116-118

Baik SH (2008) Robotic colorectal surgery. Yonsei Med J 49:891-896. doi:10.3349/ymj.2008.49.6.891

Bann S, Khan M, Hernandez J, Munz Y, Moorthy K, Datta V, Rockall T, Darzi A (2003) Robotics in surgery. J Am Coll Surg 196:784-795. doi:10.1016/s1072-7515(02)01750-7

Bencini L, Annecchiarico M, Di Marino M, Moraldi L, Perna F, Coratti A (2015) Gastrointestinal robotic surgery: challenges and developments. Robot Surg Res Rev 2:11-27

Berguer R, Smith W (2006) An ergonomic comparison of robotic and laparoscopic technique: the influence of surgeon experience and task complexity. J Surg Res 134:87-92. doi:10.1016/j.jss.2005. 10.003

Bezemer J, Cope A, Kress G, Kneebone R (2011) "Do you have another Johan?" Negotiating meaning in the operating theatre. Appl Linguist Rev 2:313-334

Bholat OS, Haluck RS, Kutz RH, Gorman PJ, Krummel TM (1999) Defining the role of haptic feedback in minimally invasive surgery. Stud Health Technol Inf 62:62-66

Bholat OS, Haluck RS, Murray WB, Gorman PJ, Krummel TM (1999) Tactile feedback is present during minimally invasive surgery. J Am Coll Surg 189:349-355. doi:10.1016/S10727515(99)00184-2

Blavier A, Nyssen A-S (2014) The effect of 2D and 3D visual modes on surgical task performance: role of expertise and adaptation processes. Cogn Technol Work 16:509-518. doi:10.1007/ s10111-014-0281-3

Booth A, Harris J, Croot E, Springett J, Campbell F, Wilkins E (2013) Towards a methodology for cluster searching to provide conceptual and contextual "richness" for systematic reviews of complex interventions: case study (CLUSTER). BMC Med Res Methodol 13:118

Cao CGL, Taylor H (2004) Effects of new technology on the operating room team. In: Khalid HM, Helander MG, Yeo AW (eds) Work with computing systems. Damai Sciences, Kuala Lumpur, pp 309-312

Catchpole K, Mishra A, Handa A, McCulloch P (2008) Teamwork and error in the operating room: analysis of skills and roles. Ann Surg 247:699-706

Cook RI, Woods DD (1996) Adapting to new technology in the operating room. Hum Factors 38:593-613. doi:10.1518/ 001872096778827224

Cook A, Douet L, Boutron I (2013) Descriptions of non-pharmacological interventions in clinical trials. BMJ 347(7924):f5212. doi:10.1136/bmj.f5212

Cristancho SM, Vanstone M, Lingard L, LeBel M-E, Ott M (2013) When surgeons face intraoperative challenges: a naturalistic model of surgical decision making. Am J Surg 205:156-162. doi:10.1016/j.amjsurg.2012.10.005

D'Annibale A, Morpurgo E, Fiscon V, Trevisan P, Sovernigo G, Orsini C, Guidolin D (2004) Robotic and laparoscopic surgery for treatment of colorectal diseases. Dis Colon Rectum 47:2162-2168. doi:10.1007/s10350-004-0711-z

de Leval MR, Carthey J, Wright DJ, Farewell VT, Reason JT (2000) Human factors and cardiac surgery: a multicenter study. J Thorac Cardiovasc Surg 119:661-672. doi:10.1016/s0022-5223(00)7 0006-7

Deutsch GB, Sathyanarayana SA, Gunabushanam V, Mishra N, Rubach E, Zemon H, Klein JDS, Denoto G 3rd (2012) Robotic vs. laparoscopic colorectal surgery: an institutional experience. Surg Endosc 26:956-963. doi:10.1007/s00464-011-1977-6 
Dobson MW, Geisler D, Fazio V, Remzi F, Hull T, Vogel J (2011) Minimally invasive surgical wound infections: laparoscopic surgery decreases morbidity of surgical site infections and decreases the cost of wound care. Colorectal Dis 13:811-815. doi:10.1111/j.1463-1318.2010.02302.x

Du X, Shen D, Li R, S Li, Ning N, Y Zhao, Z Zou, Liu N (2013) Robotic anterior resection of rectal cancer: technique and early outcome. Chin Med J 126:51-54

Edmondson AC, Bohmer RM, Pisano GP (2001) Disrupted routines: team learning and new technology implementation in hospitals. Adm Sci Q 46:685-716. doi:10.2307/3094828

Endsley MR (1995) Measurement of situation awareness in dynamic systems. Hum Factors 37:65-84. doi:10.1518/001872095779 049499

Endsley MR, Robertson MM (2000) Situation awareness in aircraft maintenance teams. Int J Ind Ergon 26:301-325. doi:10.1016/ S0169-8141(99)00073-6

Finch T, Mair F, O’Donnell C, Murray E, May C (2012) From theory to 'measurement' in complex interventions: methodological lessons from the development of an e-health normalisation instrument. BMC Med Res Methodol 12:69

Flin R, Youngson G, Yule S (2007) How do surgeons make intraoperative decisions? Qual Saf Health Care 16:235-239. doi:10.1136/qshc.2006.020743

Fung AK-Y, Aly EH (2013) Robotic colonic surgery: is it advisable to commence a new learning curve? Dis Colon Rectum 56:786-796. doi:10.1097/DCR.0b013e318285b810

Gawande AA, Zinner MJ, Studdert DM, Brennan TA (2003) Analysis of errors reported by surgeons at three teaching hospitals. Surgery 133:614-621. doi:10.1067/msy.2003.169

Gillespie BM, Chaboyer W, Longbottom P, Wallis M (2010) The impact of organisational and individual factors on team communication in surgery: a qualitative study. Int J Nurs Stud 47:732-741. doi:10.1016/j.ijnurstu.2009.11.001

Gillespie BM, Chaboyer W, Fairweather N (2012) Factors that influence the expected length of operation: results of a prospective study. BMJ Qual Saf 21:3-12. doi:10.1136/bmjqs-2011000169

Goldstraw MA, Patil K, Anderson C, Dasgupta P, Kirby RS (2007) A selected review and personal experience with robotic prostatectomy: implications for adoption of this new technology in the United Kingdom. Prostate Cancer Prostatic Dis 10:242-249

Greenhalgh T, Robert G, MacFarlane F, Bate P, Kyriakidou O (2004) Diffusion of innovations in service organizations: systematic review and recommendations. Milbank Q 82:581-629

Guerlain S, Turrentine F, Bauer D, Calland JF, Adams R (2008) Crew resource management training for surgeons: feasibility and impact. Cogn Technol Work 10:255-264. doi:10.1007/s10111007-0091-y

Guru K, Menon M (2011) How do we improve techniques in robotic surgery? J Urol 185:1186-1187. doi:10.1016/j.juro.2011.01.040

Hagen ME, Meehan JJ, Inan I, Morel P (2008) Visual clues act as a substitute for haptic feedback in robotic surgery. Surg Endosc 22:1505-1508. doi:10.1007/s00464-007-9683-0

Hance J, Rockall T, Darzi A (2004) Robotics in colorectal surgery. Dig Surg 21:339-343

Hazlehurst B, McMullen CK, Gorman PN (2007) Distributed cognition in the heart room: How situation awareness arises from coordinated communications during cardiac surgery. J Biomed Inform 40:539-551. doi:10.1016/j.jbi.2007.02.001

Healey A, Benn J (2009) Teamwork enables remote surgical control and a new model for a surgical system emerges. Cogn Technol Work 11:255-265. doi:10.1007/s10111-008-0125-0

Healey AN, Undre S, Vincent CA (2004) Developing observational measures of performance in surgical teams. Qual Saf Health Care 13:i33-i40. doi:10.1136/qshc.2004.009936
Healey A, Catchpole K, Yule S (2008) Enhancing surgical systems. Cogn Technol Work 10:251-254. doi:10.1007/s10111-007-0 090-z

Healey A, Nagpal K, Moorthy K, Vincent C (2011) Engineering the system of communication for safer surgery. Cogn Technol Work 13:1-10. doi:10.1007/s10111-010-0152-5

Helvind NM, Eriksen JR, Mogensen A, Tas B, Olsen J, Bundgaard M, Jakobsen HL, Gogenur I (2013) No differences in short-term morbidity and mortality after robot-assisted laparoscopic versus laparoscopic resection for colonic cancer: a case-control study of 263 patients. Surg Endosc 27:2575-2580. doi:10.1007/s00464013-2792-z

Higuchi T, Gettman T (2011) Robotic instrumentation, personnel and operating room set-up. In: Su L-M (ed) Atlas of robotic urologic surgery. Springer LLC, New York, pp 15-30

Ho C-M, Wakabayashi G, Nitta H, Ito N, Hasegawa Y, Takahara T (2013) Systematic review of robotic liver resection. Surg Endosc 27:732-739. doi:10.1007/s00464-012-2547-2

Huettner F, Dynda D, Ryan M, Doubet J, Crawford DL (2010) Robotic-assisted minimally invasive surgery; a useful tool in resident training - the Peoria experience, 2002-2009. Int J Med Robot Comput Assist Surg 6:386-393. doi:10.1002/rcs.342

Hull L, Arora S, Aggarwal R, Darzi A, Vincent C, Sevdalis N (2012) The impact of nontechnical skills on technical performance in surgery: a systematic review. J Am Coll Surg 214:214-230. doi:10.1016/j.jamcollsurg.2011.10.016

Hutchins E (1995a) Cognition in the wild. MIT Press, Cambridge

Hutchins E (1995b) How a cockpit remembers its speeds. Cogn Sci 19:265-288

Hutchins E, Palen L (1997) Constructing meaning from space, gesture, and speech. In: Resnick LB, Saljo R, Pontecorvo C, Burge B (eds) Discourse, tools and reasoning: essays on situated cognition. Springer, Heidelberg, pp 23-40

Johnson R, O'Hara K, Sellen A, Cousins C, Criminisi A (2011) Exploring the potential for touchless interaction in image-guided interventional radiology. CHI 2011. ACM, Vancouver

Jones A, Sethia K (2010) Robotic surgery. Ann R Coll Surg Engl 92:5-8

Kanji A, Gill RS, Shi X, Birch DW, Karmali S (2011) Roboticassisted colon and rectal surgery: a systematic review. Int J Med Robot 7:401-407. doi:10.1002/rcs.432

Kariv Y, Delaney CP (2005) Robotics in colorectal surgery. Minerva Chir 60:401-416

Klein G (2008) Naturalistic decision making. Hum Factors 50:456-460. doi:10.1518/001872008x288385

Klein KJ, Sorra JS (1996) The challenge of innovation implementation. Acad Manag Rev 21:1055-1080. doi:10.2307/259164

Koh DC-S, Tsang CB-S, Kim S-H (2011) A new application of the four-arm standard da Vinci surgical system: totally roboticassisted left-sided colon or rectal resection. Surg Endosc 25:1945-1952. doi:10.1007/s00464-010-1492-1

Kwak JM, Kim SH, Kim J, Son DN, Baek SJ, Cho JS (2011) Robotic vs laparoscopic resection of rectal cancer: short-term outcomes of a case-control study. Dis Colon Rectum 54:151-156. doi:10. 1007/DCR.0b013e3181fec4fd

Lai F, Entin E (2005) Robotic surgery and the operating room team. Proc Hum Factors Ergon Soc Annu Meet 49:1070-1073. doi:10. 1177/154193120504901115

Lanfranco AR, Castellanos AE, Desai JP et al (2004) Robotic surgery: a current perspective. Ann Surg 239:14-21

Lee EC, Rafiq A, Merrell R, Ackerman R, Dennerlein JT (2005) Ergonomics and human factors in endoscopic surgery: a comparison of manual vs telerobotic simulation systems. Surg Endosc 19:1064-1070. doi:10.1007/s00464-004-8213-6

Lim DR, Min BS, Kim MS, Alasari S, Kim G, Hur H, Baik SH, Lee KY, Kim NK (2013) Robotic versus laparoscopic anterior 
resection of sigmoid colon cancer: comparative study of longterm oncologic outcomes. Surg Endosc 27:1379-1385. doi:10. 1007/s00464-012-2619-3

Lin S, Jiang H-G, Chen Z-H, Zhou S-Y, Liu X-S, Yu J-R (2011) Meta-analysis of robotic and laparoscopic surgery for treatment of rectal cancer. World J Gastroenterol 17:5214-5220. doi:10. 3748/wjg.v17.i47.5214

Lipshitz R (1993) Coverging themes in the study of decision making in realistic settings. In: Klein GA, Orasanu J, Calderwood R, Zsambok CE (eds) Decision making in action: models and methods. Ablex, Norwood, pp 103-137

Luca F, Cenciarelli S, Valvo M, Pozzi S, Faso FL, Ravizza D, Zampino G, Sonzogni A, Biffi R (2009) Full robotic left colon and rectal cancer resection: technique and early outcome. Ann Surg Oncol 16:1274-1278. doi:10.1245/s10434-009-0366-Z

Maan ZN, Gibbins N, Al-Jabri T, D'Souza AR (2012) The use of robotics in otolaryngology-head and neck surgery: a systematic review. Am J Otolaryngol 33:137-146. doi:10.1016/j.amjoto. 2011.04.003

Manojlovich M, Squires J, Davies B, Graham I (2015) Hiding in plain sight: communication theory in implementation science. Implement Sci 10:58

Manser T (2009) Teamwork and patient safety in dynamic domains of healthcare: a review of the literature. Acta Anaesthesiol Scand 53:143-151. doi:10.1111/j.1399-6576.2008.01717.x

Manzano-Santaella A (2011) A realistic evaluation of fines for hospital discharges: Incorporating the history of programme evaluations in the analysis. Evaluation 17:21-36. doi:10.1177/ 1356389010389913

Meehan J, Sandler A (2008) Pediatric robotic surgery: a singleinstitutional review of the first 100 consecutive cases. Surg Endosc 22:177-182. doi:10.1007/s00464-007-9418-2

Mentis H, O'Hara K, Sellen A, Trivedi R (2012) Interaction proxemics and image use in neurosurgery. CHI 2012. ACM, Austin

Mishra A, Catchpole K, Dale T, McCulloch P (2008) The influence of non-technical performance on technical outcome in laparoscopic cholecystectomy. Surg Endosc 22:68-73. doi:10.1007/s00464007-9346-1

Mishra JL, Allen DK, Pearman AD (2011) Information sharing during multi-agency major incidents. 74th Annual meeting of the American Society for Information Science and Technology (ASIST 2011), New Orleans

Mosier KL, Fischer UM (2010) Judgment and decision making by individuals and teams: issues, models, and applications. Rev Hum Factors Ergon 6:198-256. doi:10.1518/ 155723410x12849346788822

Ng KH, Lim YK, Ho KS, Ooi BS, Eu KW (2009) Robotic-assisted surgery for low rectal dissection: from better views to better outcome. Singap Med J 50:763-767

Nilsen P (2015) Making sense of implementation theories, models and frameworks. Implement Sci 10:53

Noble D (1993) A model to support development of situation assessment aids. In: Klein GA, Orasanu J, Calderwood R, Zsambok CE (eds) Decision making in action: models and methods. Ablex, Norwood, pp 287-305

Nyssen A-S, Blavier A (2009) Verbal communication as a sign of adaptation in socio-technical systems: the case of robotic surgery. In: Proceedings of NDM9, the 9th international conference on naturalistic decision making. British Computer Society, London, pp 267-272

Orasanu J, Connolly T (1993) The reinvention of decision making. In: Klein GA, Orasanu J, Calderwood R, Zsambok CE (eds) Decision making in action: models and methods. Ablex, Norwood, pp 3-20
Orasanu J, Salas E (1993) Team decision making in complex environments. In: Klein GA, Orasanu J, Calderwood R, Zsambok CE (eds) Decision making in action: models and methods. Ablex, Norwood, pp 327-345

Paris CR, Salas E, Cannon-Bowers JA (2000) Teamwork in multiperson systems: a review and analysis. Ergonomics 43:1052-1075. doi:10.1080/00140130050084879

Parra-Davila E, Ramamoorthy S (2013) Lap colectomy and robotics for colon cancer. Surg Oncol Clin N Am 22:143-151, vii. doi:10. 1016/j.soc.2012.08.007

Patel VR (2006) Essential elements to the establishment and design of a successful robotic surgery programme. Int $\mathrm{J}$ Med Robot Comput Assist Surg 2:28-35. doi:10.1002/rcs.77

Patel VL, Kannampallil TG (2015) Cognitive informatics in biomedicine and healthcare. J Biomed Inform 53:3-14. doi:10. 1016/j.jbi.2014.12.007

Patel VL, Kaufman DR, Kannampallil TG (2013) Diagnostic reasoning and decision making in the context of health information technology. Rev Hum Factors Ergon 8:149-190. doi: $10.1177 / 1557234 \times 13492978$

Pawson R (2006) Evidence-based policy: a realist perspective. Sage, London

Pawson R (2013) The science of evaluation: a realist manifesto. Sage, London

Pawson R, Tilley N (1997) Realistic evaluation. Sage, London

Pawson R, Greenhalgh T, Harvey G, Walshe K (2005) Realist review-a new method of systematic review designed for complex policy interventions. J Health Serv Res Policy 10:21-34. doi:10.1258/1355819054308530

Pawson R, Greenhalgh J, Brennan C, Glidewell E (2014) Do reviews of healthcare interventions teach us how to improve healthcare systems? Soc Sci Med 114:129-137. doi:10.1016/j.socscimed. 2014.05.032

Payne TN, Pitter MC (2011) Robotic-assisted surgery for the community gynecologist: can it be adopted? Clin Obstet Gynecol 54:391-411. doi:10.1097/GRF.0b013e31822b4998

Pettersen K, McDonald N, Engen O (2010) Rethinking the role of social theory in socio-technical analysis: a critical realist approach to aircraft maintenance. Cogn Technol Work 12:181-191. doi:10.1007/s10111-009-0133-8

Porpiglia F, Morra I, Lucci Chiarissi M, Manfredi M, Mele F, Grande S, Ragni F, Poggio M, Fiori C (2013) Randomised controlled trial comparing laparoscopic and robot-assisted radical prostatectomy. Eur Urol 63:606-614. doi:10.1016/j.eururo.2012.07. 007

Pugh CM, Santacaterina S, DaRosa DA, Clark RE (2011) Intraoperative decision making: more than meets the eye. J Biomed Inform 44:486-496. doi:10.1016/j.jbi.2010.01.001

Ramirez PT, Adams S, Boggess JF, Burke WM, Frumovitz MM, Gardner GJ, Havrilesky LJ, Holloway R, Lowe MP, Magrina JF, Moore DH, Soliman PT, Yap S (2012) Robotic-assisted surgery in gynecologic oncology: a Society of Gynecologic Oncology consensus statement. Developed by the Society of Gynecologic Oncology's Clinical Practice Robotics Task Force. Gynecol Oncol 124:180-184. doi:10.1016/j.ygyno.2011.11.006

Randell R, Greenhalgh J, Hindmarsh J, Dowding D, Jayne D, Pearman A, Gardner P, Croft J, Kotze A (2014) Integration of robotic surgery into routine practice and impacts on communication, collaboration, and decision making: a realist process evaluation protocol. Implement Sci 9:52

Rawlings A, Woodland J, Vegunta R, Crawford D (2007) Robotic versus laparoscopic colectomy. Surg Endosc 21:1701-1708. doi:10.1007/s00464-007-9231-y

Robert G, Greenhalgh T, MacFarlane F, Peacock R (2010) Adopting and assimilating new non-pharmaceutical technologies into 
health care: a systematic review. J Health Serv Res Policy 15:243-250. doi:10.1258/jhsrp.2010.009137

Rogers SO Jr, Gawande AA, Kwaan M, Puopolo AL, Yoon C, Brennan TA, Studdert DM (2006) Analysis of surgical errors in closed malpractice claims at 4 liability insurers. Surgery 140:25-33. doi:10.1016/j.surg.2006.01.008

Rosness R, Evjemo TE, Haavik T, Wærø I (2015) Prospective sensemaking in the operating theatre. Cogn Technol Work 18:53-69. doi:10.1007/s10111-015-0346-y

Rousseau V, Aubé C, Savoie A (2006) Teamwork behaviors: a review and an integration of frameworks. Small Group Res 37:540-570. doi: $10.1177 / 1046496406293125$

Scales CD Jr, Jones PJ, Eisenstein EL, Preminger GM, Albala DM (2005) Local cost structures and the economics of robot assisted radical prostatectomy. J Urol 174:2323-2329. doi:10.1097/01.ju. 0000181830.43340.e7

Scarpinata R, Aly EH (2013) Does robotic rectal cancer surgery offer improved early postoperative outcomes? Dis Colon Rectum 56:253-262. doi:10.1097/DCR.0b013e3182694595

Sgarbura O, Vasilescu C (2010) The decisive role of the patient-side surgeon in robotic surgery. Surg Endosc 24:3149-3155. doi:10. 1007/s00464-010-1108-9

Simorov A, Otte RS, Kopietz C, Oleynikov D (2012) Review of surgical robotics user interface: what is the best way to control robotic surgery? Surg Endosc 26:2117-2125. doi:10.1007/ s00464-012-2182-y

Sims S, Hewitt G, Harris R (2015) Evidence of collaboration, pooling of resources, learning and role blurring in interprofessional healthcare teams: a realist synthesis. J Interprof Care 29:20-25. doi: $10.3109 / 13561820.2014 .939745$

Smith A, Smith J, Jayne DG (2006) Telerobotics: surgery for the 21st century. Surgery (Oxford) 24:74-78. doi:10.1383/surg.2006.24. 2.74

Speier C, Valacich JS, Vessey I (1999) The Influence of task interruption on individual decision making: an information overload perspective. Decis Sci 30:337-360. doi:10.1111/j.15405915.1999.tb01613.x

Spitz S (2013) Canada lags in using robotic surgery. CMAJ 185:E305-E306. doi:10.1503/cmaj.109-4429

Stahl JE, Egan MT, Goldman JM, Tenney D, Wiklund RA, Sandberg WS, Gazelle S, Rattner DW (2005) Introducing new technology into the operating room: measuring the impact on job performance and satisfaction. Surgery 137:518-526. doi:10.1016/j. surg.2004.12.015

Stanton NA, Stewart R, Harris D, Houghton RJ, Baber C, McMaster R, Salmon P, Hoyle G, Walker G, Young MS, Linsell M, Dymott $R$, Green D (2006) Distributed situation awareness in dynamic systems: theoretical development and application of an ergonomics methodology. Ergonomics 49:1288-1311. doi:10.1080/ 00140130600612762

Stefanidis D, Wang F, Korndorffer J Jr, Dunne JB, Scott D (2010) Robotic assistance improves intracorporeal suturing performance and safety in the operating room while decreasing operator workload. Surg Endosc 24:377-382. doi:10.1007/s00464-0090578-0

Toro J, Lin E, Patel A (2015) Review of robotics in foregut and bariatric surgery. Surg Endosc 29:1-8. doi:10.1007/s00464-0143646-Z

Turchetti G, Palla I, Pierotti F, Cuschieri A (2012) Economic evaluation of da Vinci-assisted robotic surgery: a systematic review. Surg Endosc 26:598-606. doi:10.1007/s00464-0111936-2

van der Schatte Olivier RH, van't Hullenaar CDP, Ruurda JP, Broeders IAMJ (2009) Ergonomics, user comfort, and performance in standard and robot-assisted laparoscopic surgery. Surg Endosc 23:1365-1371. doi:10.1007/s00464-008-0184-6

Webster JL, Cao CGL (2006) Lowering communication barriers in operating room technology. Hum Factors 48:747-758. doi:10. $1518 / 001872006779166271$

Weick KE (1995) Sensemaking in organizations. Sage, Thousand Oaks

Weigl M, Antoniadis S, Chiapponi C, Bruns C, Sevdalis N (2015) The impact of intra-operative interruptions on surgeons' perceived workload: an observational study in elective general and orthopedic surgery. Surg Endosc 29:145-153. doi:10.1007/ s00464-014-3668-6

Weldon SM, Korkiakangas T, Bezemer J, Kneebone R (2013) Communication in the operating theatre. $\mathrm{Br} \mathrm{J}$ Surg 100:1677-1688. doi:10.1002/bjs.9332

Wetzel CM, Kneebone RL, Woloshynowych M, Nestel D, Moorthy K, Kidd J, Darzi A (2006) The effects of stress on surgical performance. Am J Surg 191:5-10. doi:10.1016/j.amjsurg.2005. 08.034

Whiteside JL (2008) Robotic gynecologic surgery: a brave new world? Obstet Gynecol 112:1198-1200. doi:10.1097/AOG. 0b013e3181904919

Xiao Y, Parker SH, Manser T (2013) Teamwork and collaboration. Rev Hum Factors Ergon 8:55-102. doi:10.1177/ $1557234 \times 13495181$

Zheng B, Taylor MD, Swanström LL (2009) An observational study of surgery-related activities between nurses and surgeons during laparoscopic surgery. Am J Surg 197:497-502. doi:10.1016/j. amjsurg.2008.01.034 